\title{
IgG4-related Disease - A Systemic Disease that Deserves Attention Regardless of One's Subspecialty
}

\author{
Hideaki Hamano ${ }^{1,2}$, Eiji Tanaka ${ }^{2}$, Nobukazu Ishizaka ${ }^{3}$ and Shigeyuki Kawa ${ }^{4}$
}

\begin{abstract}
:
IgG4-related disease (IgG4-RD) is an inflammatory condition characterized by a high serum IgG4 concentration and the abundant infiltration of lymphocytes and IgG4-positive plasma cells in the tissue, as well as spatial (diverse clinical manifestations) and temporal (the possibility of recurrence) multiplicities. Since the initial documentation of IgG4-related disease in patients with autoimmune pancreatitis in 2001, a growing body of evidence has been accumulating to suggest that various-virtually all-organs can be affected by IgG4$\mathrm{RD}$. In general, steroid therapy is effective and is considered to be the first-line treatment for IgG4-RD. The precise mechanism underlying this systemic disorder has remained unknown. Considering that IgG4-RD was specified as being an intractable disease in 2015 , further studies are needed to clarify whether IgG4-RD is indeed a distinct disease entity or a complex of disorders of different etiologies and clinical conditions.
\end{abstract}

Key words: IgG4-related disease, autoimmune pancreatitis

(Intern Med 57: 1201-1207, 2018)

(DOI: 10.2169/internalmedicine.9533-17)

\section{Introduction}

IgG4-related disease (IgG4-RD), a novel clinicopathological entity that was originally proposed by Japanese researchers, is now accepted worldwide (1-6). Not infrequently, patients diagnosed with IgG4-RD are found to have multiorgan involvement in various organs/tissue, including the pancreas (7-20), bile duct (21-28), lacrimal and salivary glands (12, 29-33), orbital or periorbital tissue (34-37), pachymeninx (38-41), hypophysis $(33,41-43)$, thyroid (44-47), lungs, pleura (48-58), pericardium (58-64), aorta, artery (64-66), kidneys (67-75), prostate (76-78), mediastinum, retroperitoneum $(8,33,79-82)$, and lymph nodes (83-87). In this brief review, we describe the clinical and pathological characteristics of IgG4-RD, together with the diagnosis and treatment of the disease.

\section{The Transition from Mikulicz Disease and Autoimmune Pancreatitis to IgG4-related Disease}

In the history of IgG4-RD, the transition from Mikulicz disease and autoimmune pancreatitis has significant importance. Mikulicz disease, a disorder characterized by enlarged lacrimal and salivary glands, was first reported by Mikulicz (88). However, since the latter part of the 20th century, Mikulicz disease has been considered to be included in primary Sjögren's syndrome, due to the fact that these disorders share similar histopathological features (89).

Autoimmune pancreatitis (AIP) is an inflammatory pancreatic disorder that is characterized by pancreatic swelling and diffuse irregular narrowing of the entire main pancreatic duct (9). When AIP exhibits a mass lesion, it becomes difficult to distinguish AIP from pancreatic cancer (10). Yoshida et al. observed IgG increases in afflicted patients and cases in which steroid treatment was effective and proposed the

\footnotetext{
${ }^{1}$ Division of Medical Informatics, Shinshu University Hospital, Japan, ${ }^{2}$ Department of Internal Medicine, Gastroenterology, Shinshu University School of Medicine, Japan, ${ }^{3}$ Department of Cardiology, Osaka Medical College, Japan and ${ }^{4}$ Department of Internal Medicine, Matsumoto Dental University, Japan

Received: May 18, 2017; Accepted: September 7, 2017; Advance Publication by J-STAGE: December 27, 2017

Correspondence to Dr. Hideaki Hamano, hidehama@shinshu-u.ac.jp
} 


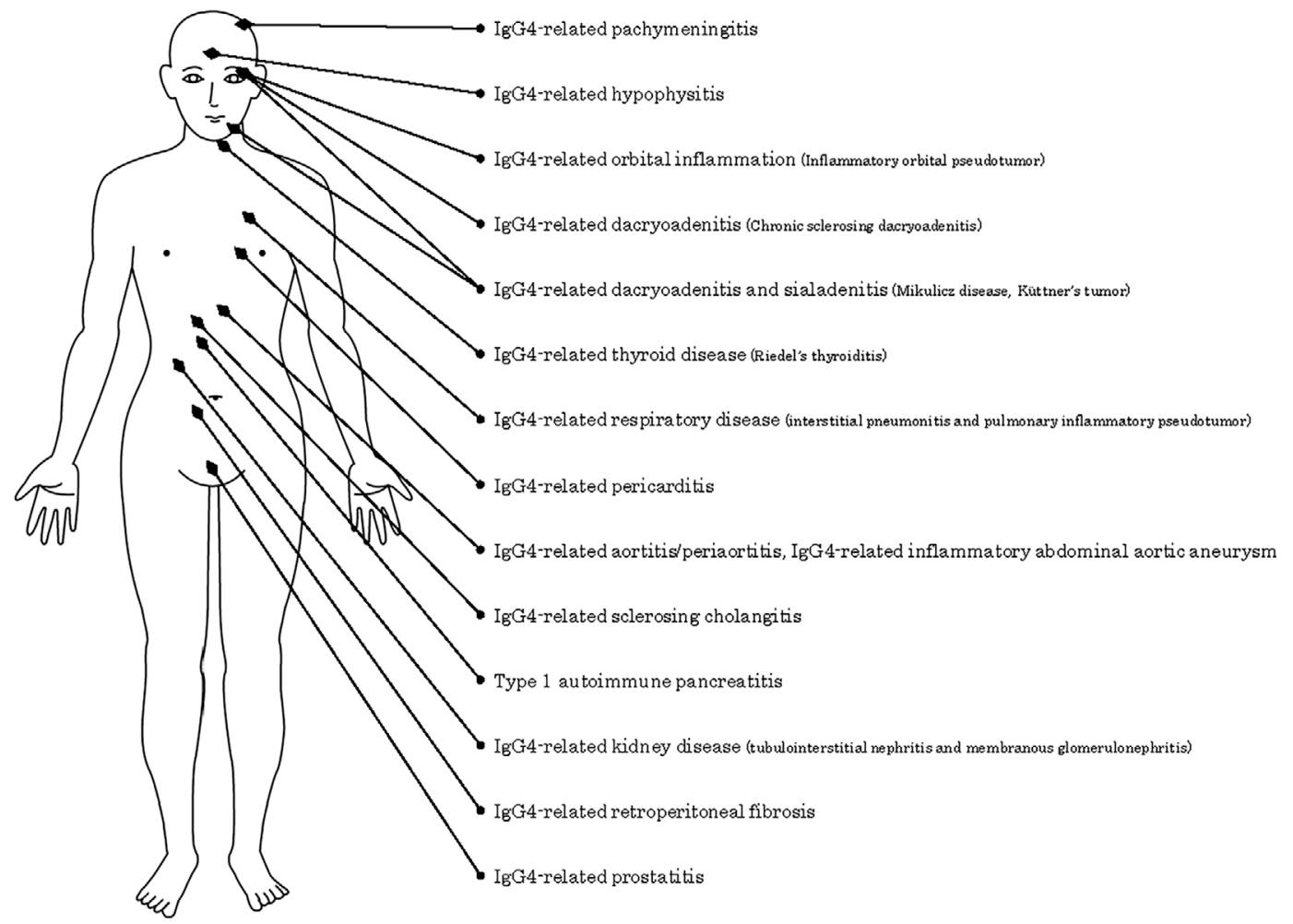

Figure 1. A key characteristic of IgG4-RD - spatial multiplicity. Spatial multiplicity can cause diverse clinical findings. The figure summarizes previous reported cases of IgG4-RD.

term AIP (11). Sarles et al. were the first to describe AIP (90) and Nakano et al. were the first to report a typical case of AIP with lachrymal and salivary lesions that was treated with steroids (91). The study by Kawaguchi et al. is renowned for its description of the typical pathological manifestations of AIP, which include marked fibrosis accompanying lymphocytic and plasmacytic infiltration (i.e., lymphoplasmacytic sclerosing pancreatitis with cholangitis; LPSP), and obliterative phlebitis (92). Since Toki et al. described the pancreatic duct findings in AIP as the diffuse irregular narrowing of the entire main duct (93), many case reports on AIP have been reported from Japan.

Hamano et al. reported that the serum IgG4 level is elevated in patients diagnosed with AIP (7), and that the abundant infiltration of IgG4-positive plasma cells was observed in the pancreas and fibroinflammatory retroperitoneal tissues (8). Based on the hematological and pathological findings, Kamisawa et al. suggested that the lachrymal and salivary lesions accompanying AIP and those accompanying Sjögren's syndrome may represent separate clinical conditions (12), and proposed the concept of IgG4-RD (1). Based on the finding that patients with Mikulicz disease have elevated serum IgG4 similar to that in AIP (29), Yamamoto and Masaki suggested that this condition is a systemic disease associated with IgG4-RD $(2,3)$.

The Comprehensive Diagnostic Criteria for IgG4-Related Disease 2011, created by Umehara et al., were the first diagnostic criteria for IgG4-RD in the world (4). As a result of Stone's efforts, the first international symposium on IgG4$\mathrm{RD}$ was held in Boston in 2011 to finally recognize IgG4-
$\mathrm{RD}$ as a global phenomenon (5).

\section{Spatial Multiplicity}

A key characteristic of IgG4-RD is that patients may exhibit diverse clinical findings. Fig. 1 summarizes the previously reported cases of IgG4-RD (1-87), which demonstrate this spatial multiplicity. Interestingly, not all cases of IgG4$\mathrm{RD}$ exhibit such a wide range of clinical findings; there are some cases in which only AIP lesions are present, while other cases show multiple lesions, such as AIP with concomitant lachrymal and salivary gland swelling. However, the question of whether diverse clinical findings such as these can truly be described as a single pathology remains under debate.

\section{Temporal Multiplicity and Recurrence}

Another characteristic feature of IgG4-RD is that patients frequently exhibit recurrence (94-97). This may be expressed as a temporal multiplicity. Spatial and temporal multiplicities are clinically problematic. There have been cases of AIP occurring 20 years after the appearance of lachrymal gland swelling, with many displaying clinical findings during recurrence that differ to those at the initial onset. Meanwhile, other cases do not exhibit recurrence, and to date no indicators have been established to predict recurrence in the initial stages of IgG4-RD. Fig. 2 shows the clinical course of the patient who had twice recurrences. Strangely, the symptom of cough was present before the onset and before each re- 


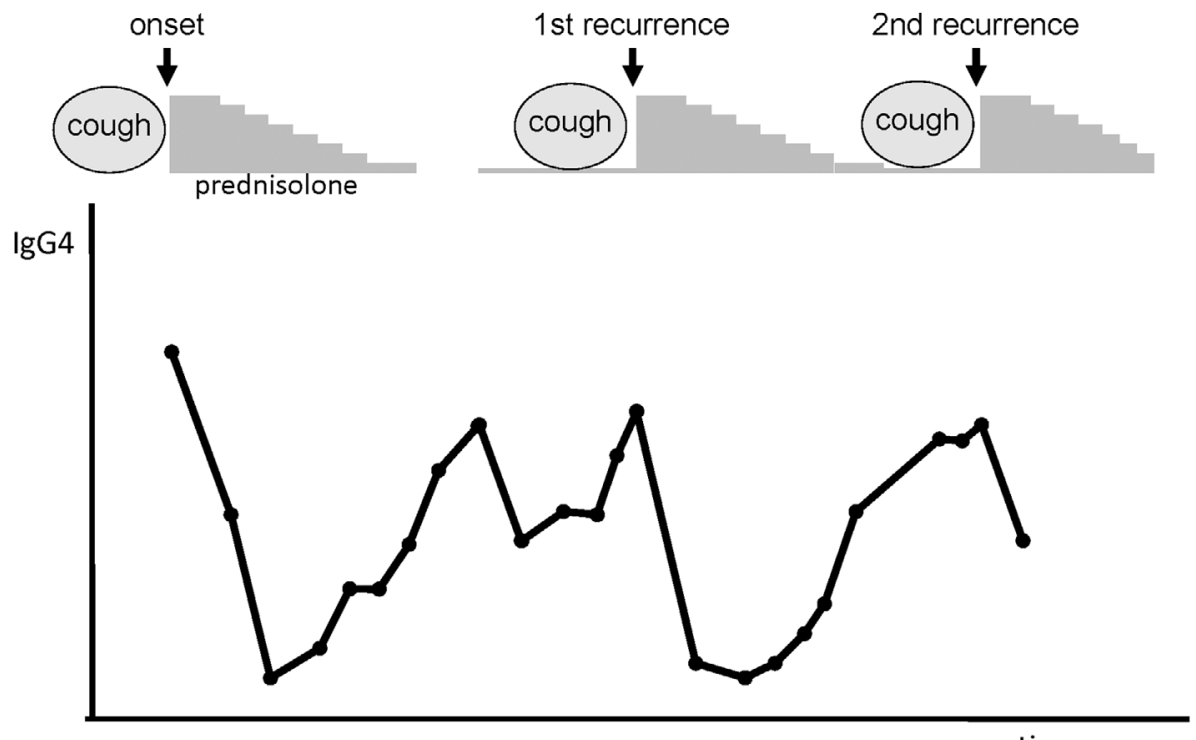

time

Figure 2. A key characteristic of IgG4-RD - temporal multiplicity and recurrence. Another characteristic feature of IgG4-RD is that patients frequently exhibit recurrence, which may be expressed as a temporal multiplicity. The figure shows the clinical course of the patient who had two recurrences. Interestingly, the patient had the symptom of cough before the onset and each of the recurrences.

Table. Comprehensive Diagnostic Criteria for IgG4-related Disease, 2011.

\author{
Comprehensive clinical diagnostic criteria for IgG4-RD \\ 1. Clinical examination showing characteristic diffuse/localized swelling or masses in single or multiple organs \\ 2. Hematological examination shows elevated serum IgG4 concentrations $(135 \mathrm{mg} / \mathrm{dL})$ \\ 3. Histopathologic examination shows: \\ (1) Marked lymphocyte and plasmacyte infiltration and fibrosis \\ (2) Infiltration of IgG4+plasma cells: ratio of $\mathrm{IgG} 4+/ \mathrm{IgG}+$ cells $>40 \%$ and $>10 \mathrm{IgG} 4+$ plasma cells/HPF \\ Definite: 1$)+2)+3$ ) \\ Probable: 1$)+3$ ) \\ Possible: 1) + 2) \\ However, it is important to differentiate IgG4-RD from malignant tumors of each organ (e.g. cancer, lymphoma) and similar \\ diseases (e.g. Sjögren's syndrome, primary sclerosing cholangitis, Castleman's disease, secondary retroperitoneal fibrosis, \\ Wegener's granulomatosis, sarcoidosis, Churg-Strauss syndrome) by additional histopathological examination. \\ Even when patients cannot be diagnosed using the CCD criteria, they may be diagnosed using organ specific diagnostic cri- \\ teria for IgG4-RD.
}

(Adapted from Umehara et al. Mod Rheumatol 2012; 22: 21-30)

currence.

\section{The Diagnosis of IgG4-RD}

The diagnosis of IgG4-RD is generally based on the detection of a high serum concentration of $\mathrm{IgG} 4$ and multiple manifestations of IgG4-positive plasma cell infiltration in affected organs/tissues $(1,4-6)$. It should be noted that other diseases may demonstrate similar clinicopathological features; thus, they should be included in the differential diagnosis.

The adoption of comprehensive diagnostic criteria (CDC) for IgG4-RD to facilitate practical use by general clinicians and non-specialists has been advocated (Table) (4). The criteria stipulate that an additional histopathological examination should be used to differentiate IgG4-RD from certain malignant disorders, including malignant lymphoma, and from other conditions with similar features, including Sjögren's syndrome, primary sclerosing cholangitis, Castleman's disease, secondary retroperitoneal fibrosis, Wegener's granulomatosis, sarcoidosis, Churg-Strauss syndrome. Physicians should be aware that, in most cases, the C-reactive protein (CRP) level is not markedly elevated in IgG4-RD, and that a high CRP level may be indicative of other mimicking conditions, such as multicentric Castleman's disease (83-87).

Even with the CDC for IgG4-RD, it is sometimes difficult to diagnose IgG4-RD because there are cases in which a high serum IgG4 concentration and/or IgG4-positive plasma cell infiltration are absent. Nevertheless, the CDC for IgG4RD seem to be advantageous due to their simplicity. 


\section{The Treatment of IgG4-RD}

Steroid treatment is effective and is considered to be the standard therapy for $\operatorname{IgG} 4-\mathrm{RD}(6,11,91)$. Although patients with organ dysfunction or other symptoms are generally considered to be eligible for this therapy, the administration of steroids in asymptomatic cases remains controversial. Treatment involves the administration of oral prednisolone (30-40 mg/day; $0.6 \mathrm{mg} /$ weight $\mathrm{kg}$ /day) over 2-4 weeks as AIP remission induction therapy, which is then progressively tapered every 1-2 weeks. Recurrence rates are relatively low in patients undergoing subsequent maintenance therapy; however, validation studies are required to confirm its utility $(91,97-99)$.

IgG4-RD frequently recurs, at which point an increased steroid dose is often effective. The rates of recurrence mayin part-depend on the speed of the steroid tapering (100). In addition to steroids, the effects of immunosuppressive agents and rituximab in patients with recurrent IgG4-RD are being investigated in clinical trials $(6,101,102)$.

\section{The Pathogenesis of IgG4-RD}

Although the etiology of IgG4-RD remains unknown, it might represent certain deranged immunological and/or allergic conditions. Previous studies have indicated that IgG4$\mathrm{RD}$ is a Th2-dependent disease in which the expression of regulatory $\mathrm{T}$ cells is promoted (103). Shiokawa et al. reported that mice that were given $\mathrm{IgG}$ from patients with IgG4-RD only exhibited lesions in organs that were affected in the patients, suggesting the presence of autoantibodies against the affected organs may have existed in the serum of patients. In addition, they reported that IgG1 had stronger pathogenicity than $\mathrm{IgG} 4$, and that $\mathrm{IgG} 4$ might modulate the pathogenicity of IgG1 (104). Taken together with the potential relationship between IgG4-RD and malignant diseases (105-108), the underlying pathogenesis requires further investigation.

\section{The Validity of IgG4-RD as a Disease Entity}

Many organ lesions have already been reported as manifestations of IgG4-RD $(1-87,94)$ according to the hematological finding of a high serum IgG4 concentration and pathological evidence of abundant IgG4-positive plasma cell infiltration. Variation has also been observed in IgG4-RD, including combinations of single-organ and multi-organ lesions (94), repeated recurrence (97-100), allergic complications $(109,110)$, decreased complement proteins (111-113), increased eosinophils $(109,110)$, increased $\operatorname{IgE}(109,120)$, and malignant complications (105-108). Considering the diversity of these manifestations, there is a strong need for further investigation to determine whether IgG4-RD is truly a single disease entity or an aggregate of several IgG4related syndromes.
One reason for the wide acceptance of IgG4-RD is that IgG4 is the most minor subclass of IgG and the appearance of large numbers of plasma cells in patients with IgG4 is very rare. Thus, it may be important to only consider IgG4 as an auxiliary diagnosis. It is also important to consider that it may not be possible to define IgG1-related disease, as the elevation of serum IgG1 and the tissue infiltration of IgG-positive cells can be observed in a wide variety of disorders.

\section{Future Directions}

We described the concept, diagnosis, and treatment of IgG4-RD. Although IgG4-RD, in general, shows a good response to steroid therapy, we should understand that-in some cases-this pathological condition might be refractory to medical therapy or recur after treatment, and that it can be life-threatening. More than 15 years has been passed since IgG4-RD was discovered. It is therefore imperative that IgG4-RD be distinguished either as a distinct disease entity or a syndrome. In addition, this clinicopathological condition should not be overlooked by health care providers, regardless of their primary specialty. The pathogenic mechanism underlying the development of this disorder should be clarified in the future to facilitate further discussion on whether IgG4-RD is indeed a distinct disease entity or whether patients who are diagnosed with this condition simply show clinicopathological characteristics that are shared by various disorders.

The authors state that they have no Conflict of Interest (COI).

\section{References}

1. Kamisawa T, Funata N, Hayashi Y, et al. A new clinicopathological entity of IgG4-related autoimmune disease. J Gastroenterol 38: 982-984, 2003.

2. Yamamoto M, Takahashi H, Hasebe $\mathrm{K}$, et al. The analysis of interleukin-6 in patients with systemic IgG4-related plasmacytic syndrome-expansion of SIPS to the territory of Castleman's disease. Rheumatology (Oxford) 48: 860-862, 2009.

3. Masaki Y, Dong L, Kurose N, et al. Proposal for a new clinical entity, IgG4-positive multiorgan lymphoproliferative syndrome: analysis of 64 cases of IgG4-related disorders. Ann Rheum Dis 68: 1310-1315, 2009.

4. Umehara H, Okazaki K, Masaki Y, et al. Comprehensive diagnostic criteria for IgG4-related disease (IgG4-RD), 2011. Mod Rheumatol 22: 21-30, 2012.

5. Stone JH, Zen Y, Deshpande V. IgG4-related disease. N Engl J Med 366: 539-551, 2012.

6. Khosroshahi A, Wallace ZS, Crowe JL, et al. International consensus guidance statement on the management and treatment of IgG4related disease. Arthritis Rheumatol 67: 1688-1699, 2015.

7. Hamano H, Kawa S, Horiuchi A, et al. High serum IgG4 concentrations in patients with sclerosing pancreatitis. N Engl J Med 344: 732-738, 2001.

8. Hamano H, Kawa S, Ochi Y, et al. Hydronephrosis associated with retroperitoneal fibrosis and sclerosing pancreatitis. Lancet 359: 1403-1404, 2002.

9. Okazaki K, Uchida K, Matsushita M, Takaoka M. Autoimmune 
pancreatitis. Intern Med 44: 1215-1223, 2005.

10. Okazaki K, Uchida K, Chiba T. Recent concept of autoimmunerelated pancreatitis. J Gastroenterol 36: 293-302, 2001.

11. Yoshida K, Toki F, Takeuchi T, Watanabe S, Shirotori K, Hayashi N. Chronic pancreatitis caused by an autoimmune abnormality. Proposal of the concept of autoimmune pancreatitis. Dig Dis Sci 40: 1561-1568, 1995.

12. Kamisawa T, Funata N, Hayashi $Y$, et al. Close relationship between autoimmune pancreatitis and multifocal fibrosclerosis. Gut 52: 683-687, 2003.

13. Horiuchi A, Kawa S, Akamatsu T, et al. Characteristic pancreatic duct appearance in autoimmune chronic pancreatitis: a case report and review of the Japanese literature. Am J Gastroenterol 93: 260263, 1998.

14. Uchida K, Okazaki K, Konishi $\mathrm{Y}$, et al. Clinical analysis of autoimmune-related pancreatitis. Am J Gastroenterol 95: 27882794, 2000

15. Horiuchi A, Kawa S, Hamano H, Hayama M, Ota H, Kiyosawa K. ERCP features in 27 patients with autoimmune pancreatitis. Gastrointest Endosc 55: 494-499, 2002.

16. Nishimori I, Tamakoshi A, Otsuki M, et al. Prevalence of autoimmune pancreatitis in Japan from a nationwide survey in 2002. J Gastroenterol. 42 (Suppl) 18: 6-8, 2007.

17. Shimosegawa $T$, Kanno A. Autoimmune pancreatitis in Japan: overview and perspective. J Gastroenterol 44: 503-517, 2009.

18. Sah RP, Chari ST, Pannala R, et al. Differences in clinical profile and relapse rate of type 1 versus type 2 autoimmune pancreatitis. Gastroenterology 139: 140-148, 2010.

19. Fijinaga $Y$, Kadoya $M$, Kawa $S$, et al. Characteristic findings in images of extra-pancreatic lesions associated with autoimmune pancreatitis. Eur J Radiol 76: 228-238, 2010.

20. Kawa S, Okazaki K, Notohara K, et al. Autoimmune pancreatitis complicated with inflammatory bowel disease and comparative study of type 1 and type 2 autoimmune pancreatitis. J Gastroenterol 50: 805-815, 2015.

21. Erkelens GW, Vleggaar FP, Lesterhuis W, van Buuren HR, van der Werf SD. Sclerosing pancreato-cholangitis responsive to steroid therapy. Lancet 354: 43-44, 1999.

22. Zen Y, Harada K, Sasaki M, et al. IgG4-related sclerosing cholangitis with and without hepatic inflammatory pseudotumor, and sclerosing pancreatitis-associated sclerosing cholangitis: do they belong to a spectrum of sclerosing pancreatitis? Am J Surg Pathol 28: 1193-1203, 2004.

23. Nakazawa T, Ohara H, Sano H, et al. Clinical differences between primary sclerosing cholangitis and sclerosing cholangitis with autoimmune pancreatitis. Pancreas 30: 20-25, 2005

24. Uehara T, Hamano H, Kawa S, et al. Distinct clinicopathological entity 'autoimmune pancreatitis-associated sclerosing cholangitis'. Pathol Int 55: 405-411, 2005.

25. Hamano H, Kawa S, Uehara T, et al. Immunoglobulin G4-related lymphoplasmacytic sclerosing cholangitis that mimics infiltrating hilar cholangiocarcinoma: part of a spectrum of autoimmune pancreatitis? Gastrointest Endosc 62: 152-157, 2005.

26. Hamano H, Umemura T, Uehara T, Kawa S, Kiyosawa K. IgG4related sclerosing cholangitis should be included as an exclusion criterion for the diagnosis of primary sclerosing cholangitis. Am J Gastroenterol 102: 691-692, 2007.

27. Nakazawa T, Ando T, Hayashi K, Naitoh I, Ohara H, Joh T. Diagnostic procedures for IgG4-related sclerosing cholangitis. J Hepatobiliary Pancreat Sci 18: 127-136, 2011.

28. Ohara H, Okazaki K, Tsubouchi H, et al. Clinical diagnostic criteria of IgG4-related sclerosing cholangitis 2012. J Hepatobiliary Pancreat Sci 19: 536-542, 2012.

29. Yamamoto M, Ohara M, Suzuki C, et al. Elevated IgG4 concentrations in serum of patients with Mikulicz's disease. Scand J Rheumatol 33: 432-433, 2004
30. Takahira M, Kawano M, Zen Y, Minato H, Yamada K, Sugiyama K. IgG4-related chronic sclerosing dacryoadenitis. Arch Ophthalmol 125: 1575-1578, 2007.

31. Cheuk W, Yuen HK, Chan AC, et al. Ocular adnexal lymphoma associated with IgG4+ chronic sclerosing dacryoadenitis: a previously undescribed complication of IgG4-related sclerosing disease. Am J Surg Pathol 32: 1159-1167, 2008.

32. Kitagawa S, Zen Y, Harada K, et al. Abundant IgG4-positive plasma cell infiltration characterizes chronic sclerosing sialadenitis (Küttner's tumor). Am J Surg Pathol 29: 783-791, 2005.

33. Tanabe T, Tsushima K, Yasuo M, et al. IgG4-associated multifocal systemic fibrosis complicating sclerosing sialadenitis, hypophysitis, and retroperitoneal fibrosis, but lacking pancreatic involvement. Intern Med 45: 1243-1247, 2006.

34. Sato $\mathrm{Y}$, Ohshima K, Ichimura $\mathrm{K}$, et al. Ocular adnexal IgG4related disease has uniform clinicopathology. Pathol Int 58: 465470, 2008.

35. Wallace ZS, Khosroshahi A, Jakobiec FA, et al. IgG4-related systemic disease as a cause of "idiopathic" orbital inflammation, including orbital myositis, and trigeminal nerve involvement. Surv Ophthalmol 57: 26-33, 2012.

36. Sogabe Y, Ohshima K, Azumi A, et al. Location and frequency of lesions in patients with IgG4-related ophthalmic diseases. Graefes Arch Clin Exp Ophthalmol 252: 531-538, 2014.

37. Andrew NH, Sladden N, Kearney DJ, Selva D. An analysis of IgG 4-related disease (IgG4-RD) among idiopathic orbital inflammations and benign lymphoid hyperplasias using two consensusbased diagnostic criteria for IgG4-RD. Br J Ophthalmol 99: 376$381,2015$.

38. Lindstrom KM, Cousar JB, Lopes MB. IgG4-related meningeal disease: clinico-pathological features and proposal for diagnostic criteria. Acta Neuropathol 120: 765-776, 2010.

39. Kim EH, Kim SH, Cho JM, et al. Immunoglobulin G4-related hypertrophic pachymeningitis involving cerebral parenchyma. J Neurosurg 115: 1242-1247, 2011.

40. Wallace ZS, Carruthers MN, Khosroshahi A, et al. IgG4-related disease and hypertrophic pachymeningitis. Medicine (Baltimore) 92: 206-216, 2013.

41. Joshi D, Jager R, Hurel S, et al. Cerebral involvement in IgG4related disease. Clin Med (Lond) 15: 130-134, 2015.

42. Shimatsu A, Oki Y, Fujisawa I, Sano T. Pituitary and stalk lesions (infundibulo-hypophysitis) associated with immunoglobulin G4related systemic disease: an emerging clinical entity. Endocr J 56: 1033-1041, 2009.

43. Wong S, Lam WY, Wong WK, Lee KC. Hypophysitis presented as inflammatory pseudotumor in immunoglobulin G4-related systemic disease. Hum Pathol 38: 1720-1723, 2007.

44. Komatsu K, Hamano H, Ochi Y, et al. High prevalence of hypothyroidism in patients with autoimmune pancreatitis. Dig Dis Sci 50: 1052-1057, 2005.

45. Li Y, Nishihara E, Hirokawa M, Taniguchi E, Miyauchi A, Kakudo K. Distinct clinical, serological, and sonographic characteristics of hashimoto's thyroiditis based with and without IgG4positive plasma cells. J Clin Endocrinol Metab 95: 1309-1317, 2010.

46. Deshpande V, Huck A, Ooi E, Stone JH, Faquin WC, Nielsen GP. Fibrosing variant of Hashimoto thyroiditis is an IgG4 related disease. J Clin Pathol 65: 725-728, 2012.

47. Watanabe T, Maruyama M, Ito T, et al. Clinical features of a new disease concept, IgG4-related thyroiditis. Scand J Rheumatol 42: 325-330, 2013.

48. Taniguchi T, Ko M, Seko S, et al. Interstitial pneumonia associated with autoimmune pancreatitis. Gut 53: 770, 2004.

49. Zen Y, Kitagawa S, Minato $\mathrm{H}$, et al. IgG4-positive plasma cells in inflammatory pseudotumor (plasma cell granuloma) of the lung. Hum Pathol 36: 710-717, 2005. 
50. Hirano K, Kawabe T, Komatsu Y, et al. High-rate pulmonary involvement in autoimmune pancreatitis. Intern Med J 36: 58-61, 2006.

51. Hamed G, Tsushima K, Yasuo M, et al. Inflammatory lesions of the lung, submandibular gland, bile duct and prostate in a patient with IgG4-associated multifocal systemic fibrosclerosis. Respirology 12: 455-457, 2007.

52. Tsushima $\mathrm{K}$, Tanabe $\mathrm{T}$, Yamamoto $\mathrm{H}$, et al. Pulmonary involvement of autoimmune pancreatitis. Eur J Clin Invest 39: 714-722, 2009.

53. Ito $M$, Yasuo $M$, Yamamoto $H$, et al. Central airway stenosis in a patient with autoimmune pancreatitis. Eur Respir J 33: 680-683, 2009.

54. Inoue $\mathrm{D}$, Zen $\mathrm{Y}$, Abo $\mathrm{H}$, et al. Immunoglobulin G4-related lung disease: CT findings with pathologic correlations. Radiology 251: 260-270, 2009

55. Yamamoto H, Suzuki T, Yasuo M, et al. IgG4-related pleural disease diagnosed by a re-evaluation of chronic bilateral pleuritis in a patient who experienced occasional acute left bacterial pleuritis. Intern Med 50: 893-897, 2011.

56. Matsui S, Taki H, Shinoda K, et al. Respiratory involvement in IgG4-related Mikulicz's disease. Mod Rheumatol 22: 31-39, 2012.

57. Matsui S, Yamamoto $H$, Minamoto S, Waseda Y, Mishima M, Kubo K. Proposed diagnostic criteria for IgG4-related respiratory disease. Respir Investig 54: 130-132, 2016.

58. Rossi G, Marchioni A, Guicciardi N, Cadioli A, Cavazza A. Recurrent pleural and pericardium effusions in a white woman with IgG4-related syndrome. Am J Surg Pathol 33: 802-803, 2009.

59. Sugimoto T, Morita $Y$, Isshiki $\mathrm{K}$, et al. Constrictive pericarditis as an emerging manifestation of hyper-IgG4 disease. Int J Cardiol 130: e100-e101, 2008.

60. Sakamoto A, Nagai R, Saito K, et al. Idiopathic retroperitoneal fibrosis, inflammatory aortic aneurysm, and inflammatory pericarditis-retrospective analysis of 11 case histories. J Cardiol 59: 139-146, 2012.

61. Sekiguchi H, Horie R, Utz JP, Ryu JH. IgG4-related systemic disease presenting with lung entrapment and constrictive pericarditis. Chest 142: 781-783, 2012.

62. Morita $\mathrm{T}$, Izawa $\mathrm{A}$, Hamano $\mathrm{H}$, et al. Significant pericardial in volvement of immunoglobulin G4-related disease. Ann Thorac Surg 98: e47-e49, 2014.

63. Mori K, Yamada K, Konno $\mathrm{T}$, et al. Pericardial involvement in IgG4-related disease. Intern Med 54: 1231-1235, 2015.

64. Ishizaka N, Sakamoto A, Imai Y, Terasaki F, Nagai R. Multifocal fibrosclerosis and IgG4-related disease involving the cardiovascular system. J Cardiol 59: 132-138, 2012.

65. Kasashima S, Zen Y, Kawashima A, et al. Inflammatory abdominal aortic aneurysm: close relationship to IgG4-related periaortitis. Am J Surg Pathol 32: 197-204, 2008.

66. Kasashima S, Zen Y, Kawashima A, Endo M, Matsumoto Y, Kasashima F. A new clinicopathological entity of IgG4-related inflammatory abdominal aortic aneurysm. J Vasc Surg 49: 12641271,2009

67. Takeda S, Haratake J, Kasai T, Takaeda C, Takazakura E. IgG4associated idiopathic tubulointerstitial nephritis complicating autoimmune pancreatitis. Nephrol Dial Transplant 19: 474-476, 2004.

68. Uchiyama-Tanaka Y, Mori Y, Kimura T, et al. Acute tubulointerstitial nephritis associated with autoimmune-related pancreatitis. Am J Kidney Dis 43: e18-e25, 2004.

69. Watson SJ, Jenkins DA, Bellamy CO. Nephropathy in IgG4related systemic disease. Am J Surg Pathol 30: 1472-1477, 2006.

70. Murashima M, Tomaszewski J, Glickman JD. Chronic tubulointerstitial nephritis presenting as multiple renal nodules and pancreatic insufficiency. Am J Kidney Dis 49: e7-e10, 2007.

71. Saeki T, Saito A, Yamazaki H, et al. Tubulointerstitial nephritis associated with IgG4-related systemic disease. Clin Exp Nephrol 11:
168-173, 2007.

72. Yoneda K, Murata K, Katayama K, et al. Tubulointerstitial nephritis associated with IgG4-related autoimmune disease. Am J Kidney Dis 50: 455-462, 2007.

73. Saeki T, Nishi S, Ito $T$, et al. Renal lesions in IgG4-related systemic disease. Intern Med 46: 1365-1371, 2007.

74. Saeki T, Nishi S, Imai N, et al. Clinicopathological characteristics of patients with IgG4-related tubulointerstitial nephritis. Kidney Int 78: 1016-1023, 2010.

75. Kawano M, Saeki T, Nakashima H, et al. Proposal for diagnostic criteria for IgG4-related kidney disease. Clin Exp Nephrol 15: 615-626, 2011.

76. Yoshimura Y, Takeda S, Ieki Y, Takazakura E, Koizumi H, Takagawa $\mathrm{K}$. IgG4-associated prostatitis complicating autoimmune pancreatitis. Intern Med 45: 897-901, 2006.

77. Nishimori I, Kohsaki T, Onishi S, et al. IgG4-related autoimmune prostatitis: two cases with or without autoimmune pancreatitis. Intern Med 46: 1983-1989, 2007.

78. Uehara $T$, Hamano $H$, Kawakami $M$, et al. Autoimmune pancreatitis-associated prostatitis: distinct clinicopathological entity. Pathol Int 58: 118-125, 2008.

79. Zen Y, Sawazaki A, Miyayama S, Notsumata K, Tanaka N, Nakanuma Y. A case of retroperitoneal and mediastinal fibrosis exhibiting elevated levels of IgG4 in the absence of sclerosing pancreatitis (autoimmune pancreatitis). Hum Pathol 37: 239-243, 2006.

80. Taniguchi T, Kobayashi H, Fukui S, Ogura K, Saiga T, Okamoto M. A case of multifocal fibrosclerosis involving posterior mediastinal fibrosis, retroperitoneal fibrosis, and a left seminal vesicle with elevated serum IgG4. Hum Pathol 37: 1237-1239, 2006.

81. Zen Y, Onodera M, Inoue D, et al. Retroperitoneal fibrosis: a clinicopathologic study with respect to immunoglobulin G4. Am J Surg Pathol 33: 1833-1839, 2009.

82. Khosroshahi A, Carruthers MN, Stone JH, et al. Rethinking Ormond's disease: "idiopathic" retroperitoneal fibrosis in the era of IgG4-related disease. Medicine (Baltimore) 92: 82-91, 2013.

83. Ishida F, Kitano K, Kobayashi H, Saito H, Kiyosawa K. Elevated IgG4 levels in a case with multicentric Castleman's disease. Br J Haematol 99: 981-982, 1997.

84. Sato Y, Kojima M, Takata K, et al. Systemic IgG4-related lymphadenopathy: a clinical and pathologic comparison to multicentric Castleman's disease. Mod Pathol 22: 589-599, 2009.

85. Kojima M, Nakamura N, Motoori T, et al. Castleman's disease of the retroperitoneum: with special reference to IgG4-related disorder. J Clin Exp Hematop 50: 39-44, 2010.

86. Sato Y, Kojima M, Takata K, et al. Multicentric Castleman's disease with abundant IgG4-positive cells: a clinical and pathological analysis of six cases. J Clin Pathol 63: 1084-1089, 2010.

87. Kojima M, Nakamura N, Motoori T, Shimizu K, Haratake J, Nakamura S. IgG4-related disorder of the retroperitoneum resembling Castleman's disease plasma cell type: a report of 2 cases. Int J Surg Pathol 19: 220-224, 2011.

88. Mikulicz J. Über eine eigenartige symmetrishe Erkrankung der Tränen und Mundspeicheldrusen. Beitr Z, Chir Fesrschr F. Theodor Billroth, Stuttgart, 1892: 610-630 (in German).

89. Morgan WS, Castleman B. A clinicopathologic study of "Mikulicz's disease." Am J Pathol 29: 471-503, 1953.

90. Sarles H, Sarles JC, Muratore R, Guien C. Chronic inflammatory sclerosis of the pancreas-an autonomous pancreatic disease? Am J Dig Dis 6: 688-698, 1961.

91. Nakano S, Takeda I, Kitamura K, Watahiki H, Iinuma Y, Takenaka M. Vanishing tumor of the abdomen in patient with Sjögren's syndrome. Digestive Disease 23: 75S-79S, 1978.

92. Kawaguchi K, Koike M, Tsuruta K, Okamoto A, Tabata I, Fujita N. Lymphoplasmacytic sclerosing pancreatitis with cholangitis: a variant of primary sclerosing cholangitis extensively involving 
pancreas. Hum Pathol 22: 387-395, 1991.

93. Toki F, Kozu T, Oi I, Nakasako T, Suzuki M, Hanyu F. An unusual type of chronic pancreatitis showing diffuse irregular narrowing of the entire main pancreatic duct on ERCP- A report of four cases [abstract]. Endoscopy 24: 640, 1992.

94. Hamano H, Arakura N, Muraki T, Ozaki Y, Kiyosawa K, Kawa S. Prevalence and distribution of extrapancreatic lesions complicating autoimmune pancreatitis. J Gastroenterol 41: 1197-1205, 2006.

95. Takayama M, Hamano H, Ochi Y, et al. Recurrent attacks of autoimmune pancreatitis result in pancreatic stone formation. Am J Gastroenterol 99: 932-937, 2004.

96. Wallace ZS, Mattoo H, Mahajan VS, et al. Predictors of disease relapse in IgG4-related disease following rituximab. Rheumatology (Oxford) 55: 1000-1008, 2016.

97. Masamune A, Nishimori I, Kikuta K, et al. Randomised controlled trial of long-term maintenance corticosteroid therapy in patients with autoimmune pancreatitis. Gut 66: 487-494, 2017.

98. Kamisawa T, Shimosegawa T, Okazaki K, et al. Standard steroid treatment for autoimmune pancreatitis. Gut 58: 1504-1507, 2009.

99. Kamisawa $\mathrm{T}$, Okazaki $\mathrm{K}$, Kawa $\mathrm{S}$, et al. Japanese consensus guidelines for management of autoimmune pancreatitis: III. Treatment and prognosis of AIP. J Gastroenterol 45: 471-477, 2010.

100. Shimizu K, Tahara J, Takayama Y, et al. Assessment of the rate of decrease in serum IgG4 level of autoimmune pancreatitis patients in response to initial steroid therapy as a predictor of subsequent relapse. Pancreas 45: 1341-1346, 2016.

101. Khosroshahi A, Bloch DB, Deshpande V, Stone JH. Rituximab therapy leads to rapid decline of serum IgG4 levels and prompt clinical improvement in IgG4related systemic disease. Arthritis Rheum 62: 1755-1762, 2010.

102. Khosroshahi A, Carruthers MN, Deshpande V, Unizony S, Bloch DB, Stone JH. Rituximab for the treatment of IgG4-related disease: lessons from 10 consecutive patients. Medicine (Baltimore) 91: 57-66, 2012.

103. Zen Y, Fujii T, Harada K, et al. Th2 and regulatory immune reactions are increased in immunoglobin G4-related sclerosing pan- creatitis and cholangitis. Hepatology 45: 1538-1546, 2007.

104. Shiokawa M, Kodama Y, Kuriyama K, et al. Pathogenicity of IgG in patients with IgG4-related disease. Gut 65: 1322-1332, 2016.

105. Shiokawa M, Kodama Y, Yoshimura K, et al. Risk of cancer in patients with autoimmune pancreatitis. Am J Gastroenterol 108: 610-617, 2013.

106. Asano J, Watanabe $T$, Oguchi $T$, et al. Association between immunoglobulin G4-related disease and malignancy within 12 years after diagnosis: an analysis after longterm followup. J Rheumatol 42: 2135-2142, 2015.

107. Hirano K, Isayama H, Tada M, Koike K. Association between autoimmune pancreatitis and malignancy. Clin J Gastroenterol 7: 200-204, 2014.

108. Wallace ZS, Wallace CJ, Lu N, Choi HK, Stone JH. Association of IgG4-related disease with history of malignancy. Arthritis Rheumatol 68: 2283-2289, 2016.

109. Kamisawa T, Anjiki H, Egawa N, Kubota N. Allergic manifestations in autoimmune pancreatitis. Eur J Gastroenterol Hepatol 21: 1136-1139, 2009.

110. Della Torre E, Mattoo H, Mahajan VS, Carruthers M, Pillai S, Stone JH. Prevalence of atopy, eosinophilia, and IgE elevation in IgG4-related disease. Allergy 69: 269-272, 2014.

111. Muraki T, Hamano H, Ochi Y, et al. Autoimmune pancreatitis and complement activation system. Pancreas 32: 16-21, 2006.

112. Saeki T, Ito T, Yamazaki H, Imai N, Nishi S. Hypocomplementemia of unknown etiology: an opportunity to find cases of IgG4positive multi-organ lymphoproliferative syndrome. Rheumatol Int 30: 99-103, 2009.

113. Kawa S. The immunobiology of immunoglobulin G4 and complement activation pathways in IgG4-related disease. Curr Top Microbiol Immunol 401: 61-73, 2017.

The Internal Medicine is an Open Access article distributed under the Creative Commons Attribution-NonCommercial-NoDerivatives 4.0 International License. To view the details of this license, please visit (https://creativecommons.org/licenses/ by-nc-nd/4.0/).

(C) 2018 The Japanese Society of Internal Medicine Intern Med 57: 1201-1207, 2018 